\title{
Supressão da resposta imunitária humoral causada por citrinina efeito imunotóxico da citrinina
}

\author{
Humoral immunoresponse discontinuance caused by citrinin
}

\author{
Cristiane Albuquerque de Carvalho e Ronald Bastos Freire*
}

\begin{abstract}
Resumo
O presente trabalho foi realizado com a finalidade de avaliar o efeito imunotóxico causado por exposição a baixas doses de citrinina $\left(2,5 \mathrm{mg} \cdot \mathrm{Kg}^{-1}\right)$. Para tanto, lotes de cinco camundongos albinos foram expostos à micotoxina antes, durante e após imunização com antígeno inerte (eritrócitos de carneiro - SRBC). Sete dias após tratamento, os animais foram sangrados e os títulos de anticorpos anti-SRBC e de complemento foram determinados, em relação a um grupo controle não intoxicado. Observou-se que a citrinina causou diminuição nos títulos de anticorpos primários de todos os grupos de animais intoxicados. A intoxicação antes e após à imunização provocou uma diminuição nos títulos médios de anticorpos específicos equivalente a $87,5 \%$. A exposição simultânea a imunização gerou uma diminuição de $75 \%$. Houve, também, uma marcante redução nos níveis de complemento circulante, detectada nos animais previamente intoxicados $(93,75 \%)$, ou intoxicados juntamente com a imunização $(87,5 \%)$. Os efeitos relativos da citrinina sobre populações linfocitárias e sobre os processos inflamatórios e de apresentação de antígenos também foram discutidos.
\end{abstract}

Palavras-chave: citrinina; micotoxinas; imunossupressão; imunidade humoral; cumarinas.

\begin{abstract}
The present paper was done in order to determinate the immunotoxic effect caused by low dose exposure to citrinin $\left(2,5 \mathrm{mg} . \mathrm{Kg}^{-1}\right)$. Doing so, groups of five albino mice were submitted to citrinin before, concomitantly and after immunization with inert antigen (sheep red blood cells - SRBC). The animals were bleed seven days following the mycotoxin exposure and, the antibodies and complement titration determined. and compared to a not-intoxicated control group. It was detected a decrease of antibodies titration in all the intoxicated animals. The citrinin exposure done before, as well as after SRBC sensitization caused a lowering of $87.5 \%$ on the primary antibodies level. The simultaneous exposure, added to SRBC sensitization, caused a dropping equivalent to $75 \%$. A remarkable complement lowering was also demonstrated on the previously intoxicated (93.75\%), as well as, on the animals concomitantly sensitized and intoxicated with citrinin (87.5\%). The effects of citrinin on $\mathrm{T}$ lymphocytes subsets, inflammatory processes and cellular presentation of was also discussed.
\end{abstract}

Keywords: citrinin; mycotoxins; immune-suppression; humoral immunity; coumarins.

\section{Introdução}

A citrinina é um subproduto metabólico de origem cumarínica, oriundo do crescimento de várias espécies de fungos dos gêneros Penicillium e Aspergillus. A citrinina, assim como outras micotoxinas, é produzida durante o desenvolvimento fúngico em grãos, alimentos processados e produtos alimentícios oriundos, ou não, de processamentos e manipulações em citricultura. O consumo de baixas concentrações por animais sensiveis às micotoxinas pode conduzir à morte dentro de poucas horas. O mais comum é a ocorrência de intoxicações que variam entre agudas e crônicas, afetando, principalmente, os animais criados sob regime de confinamento, tais como as aves e os suínos. Em geral, a saúde e produtividade de animais alimentados com produtos contaminados com concentrações subletais de citrinina são seriamente prejudicados. Essa micotoxina modula a resposta inflamatória em aves e mamíferos, interferindo em pro- cessos de digestão e secreção de mediadores a partir de células imunocompetentes (Herzog-Soares, 1994 e Souza et al., 1997). Uma vez que os componentes do sistema complemento são secretados por fagócitos, durante os processos inflamatórios, os efeitos comumente atribuídos às diversas micotoxinas sobre a síntese protéica, podem acarretar deficiências na sua produção, permitindo, assim, a permanência de agentes infecciosos e ocorrência de infecções oportunistas (Corrier, 1991 e Freire et al., 1996). Acredita-se que a ação supressiva de micotoxinas sobre a resposta inflamatória tenha, do mesmo modo, um efeito bastante significativo sobre a resposta adaptativa humoral em mamíferos diversos (Freire et al., 1996). Em experimentos realizados anteriormente, a citrinina foi caracterizada por não afetar a produção de anticorpos (Reddy et al., 1988 e Corrier, 1991), a despeito de causar modificações drásticas nos niveis de leucócitos circulantes, com conseqüente leucopenia (Reddy et al., 1988; Herzog-Soares, 1997). Recentemente, verificou-se que a

\footnotetext{
* Laboratório de Imunologia - Núcleo de Sanidade Animal - UFRRJ/Embrapa - Departamento de Microbiologia e Imunologia Veterinária - DMIV - Universidade Federal Rural do Rio de Janeiro - UFRRJ. Antiga rodovia Rio - São Paulo Km 47 CEP 23890-000 Seropédica, RJ, Brasil.
} 
citrinina também pode estar associada a uma indução de blastogênese linfocitária (Souza et al., 1999). No presente trabalho, procurou-se determinar os efeitos da intoxicação subclínica por citrinina sobre a atividade do sistema complemento, assim como sobre resposta imune humoral para antígenos inertes, durante diferentes fases de imunização, utilizando camundongos albinos (Swiss Webstern) como modelo experimental.

\section{Material e métodos}

Micotoxina: Utilizou-se citrinina purificada, em estado cristalino, gentilmente fornecida pelo Centro de Micologia e Micotoxicologia (CMM)-Convênio Sanidade Animal UFRRJ / EMBRAPA, com grau de pureza analítica superior a $95 \%$. A micotoxina foi solubilizada em tampão carbonato-bicarbonato (CCB - 26 partes de uma solução contendo $21,2 \mathrm{~g}$ de $\mathrm{Na}_{2} \mathrm{CO}_{3}$ em $1000 \mathrm{~mL}$ adicionados a 74 partes de uma solução contendo $16,8 \mathrm{~g}$ de $\mathrm{NaHCO}_{3}$ para $1000 \mathrm{~mL}, \mathrm{pH} \mathrm{9,5)} \mathrm{e,}$ posteriormente, diluída em $0,1 \mathrm{M}$ de salina tamponada com fosfatos (PBS $0,1 \mathrm{M}-8,0 \mathrm{~g}$ de $\mathrm{NaCl} ; 0,2 \mathrm{~g}$ de $\mathrm{KCl} ; 1,2 \mathrm{~g}$ de $\mathrm{Na}_{2} \mathrm{HPO}_{4} ; 0,2 \mathrm{~g}$ de $\mathrm{KH}_{2} \mathrm{PO}_{4} ; \mathrm{H}_{2} \mathrm{O}$ q.s.p. $\left.1000 \mathrm{~mL}, \mathrm{pH} 7,2\right)$.

Animais: Utilizaram-se trinta camundongos suiço albinos, machos, com duas semanas de vida, pesando aproximadamente 25 gramas, fornecidos pelo biotério central da UFF, Niterói, RJ. Os animais foram mantidos em caixas apropriadas, alimentados com ração comercial, livre de micotoxinas, e água potável ad libitum.

Sensibilização dos animais: Os animais foram imunizados de acordo com metodologia clássica (Harlow e Lane, 1988), através da inoculação intraperitoneal de $1 \mathrm{~mL}$ de uma suspensão de eritrócitos de carneiro (SRBC) a 2,5\% em PBS a $0,1 \mathrm{M}, \mathrm{pH} 7,2$. Grupos de cinco animais foram sensibilizados antes, durante e após o tratamento com citrinina, respectivamente, e estudados comparativamente a três grupos de cinco animais controle, que não foram tratados com micotoxinas. Todos os experimentos foram realizados com três repetições. Após um intervalo de sete dias, obtiveram-se amostras de soro de todos os animais, a partir da sangria na veia mamária esquerda, tal como descrito na literatura (Hudson e Hay, 1991). Os soros foram agrupados, de acordo com a sensibilização, por SRBC e com o tratamento com citrinina, e divididos em dois lotes: o primeiro, relativo às amostras de soro inativadas pela incubação a $56 \pm 1^{\circ} \mathrm{C}$ durante 30 minutos, e o segundo lote constituído pelas amostras não inativadas (soro fresco). Os diferentes agrupamentos e seus respectivos lotes foram acondicionados em frascos apropriados, adicionados de $0,01 \%$ de Timerosal e mantidos a $-20 \pm$ $1^{\circ} \mathrm{C}$, até o momento de uso.

Intoxicação experimental: Os camundongos foram experimentalmente tratados com uma dose equivalente a $0,028 \%$ da $\mathrm{DL}_{50 \%}$ de $89 \mathrm{mg} / \mathrm{kg}$ anteriormente estabelecida para essa espécie animal (Terse et al., 1993). A micotoxina foi administrada intraperitonealmente na proporção de $2,5 \mathrm{mg} / \mathrm{kg}$ a grupos de cinco animais, excetuando-se o grupo controle que recebeu somente o veículo (PBS, 0,1M, pH 7,2).

Dosagem do complemento: Os níveis séricos de complemento foram avaliados utilizando-se o soro fresco, não inativado, recém-obtido da exsangüinação dos animais. Utilizou-se metodologia clássica (Hudson e Hay, 1991). As dife- rentes amostras de soro de cada agrupamento experimental foram diluídas serialmente, de 1:2 até 1:4096, em microplacas de sorologia (Falcon Co. Ltda, USA). Sobre as amostras de soro diluídas, adicionaram-se $25 \mu \mathrm{L}$ de SRBC a $2,5 \%$ em PBS $0,1 \mathrm{M}, \mathrm{pH} 7,2$ e $25 \mu \mathrm{L}$ de duas unidades líticas de hemolisina de camundongos SW, anti-SRBC, preparadas no Setor de Imunologia do Departamento de Microbiologia e Imunologia Veterinária (DMIV) da UFRRJ. Foram feitos controles da hemolisina, dos eritrócitos de carneiro (SRBC) e dos soros dos camundongos a serem testados com o intuito de garantir que não ocorreriam hemólises por motivos distintos à fixação do complemento pelo sistema hemolítico (SRBC - Hemolisina). As microplacas foram incubadas a $37 \pm 1^{\circ} \mathrm{C}$ durante 40 minutos e analisadas quanto ao título médio de complemento existente em cada agrupamento de soros. Considerou-se como título a maior diluição do soro teste capaz de causar hemólise frente ao sistema hemolítico.

Dosagem de anticorpos: A titulação dos anticorpos anti-SRBC, produzidos pelo primocontato dos diferentes agrupamentos uma semana antes, foi realizada através do método clássico de fixação do complemento (Hudson e Hay, 1991), visto que esses seriam, em sua maioria, pertencentes à classe IgM. Para tanto, procedeu-se o ensaio, utilizando-se como fonte de hemolisina os soros inativados, obtidos de cada um dos grupos. Uma vez que o tratamento a $56 \pm 1^{\circ} \mathrm{C}$ elimina a atividade complementar do soro, acrescentaram-se a cada diluição dos diferentes agrupamentos, $25 \mu \mathrm{L}$ de SRBC a $2,5 \%$ e $2.5 \mu \mathrm{L}$ de uma solução contendo duas unidades de complemento de soro fresco de coelho preparadas no Setor de Imunologia do DMIV da UFRRJ. Foram feitos controles do complemento, dos eritrócitos de carneiro (SRBC) e dos soros dos camundongos a serem testados com o intuito de garantir que não ocorreriam hemólises por motivos distintos à fixação do complemento pela existência de anticorpos fixadores do complemento nos soros dos animais. As microplacas foram incubadas a $37 \pm 1^{\circ} \mathrm{C}$ durante 40 minutos e analisadas quanto ao título médio de anticorpos existentes em cada agrupamento de soros. Considerou-se como título a maior diluição do soro teste capaz de causar hemólise frente ao complemento.

Análise estatística dos resultados: Procedeu-se o teste de Tuckey, considerando-se $p<0,01$ tal como descrito por Souza e colaboradores (1999).

\section{Resultados e discussão}

A freqüente ocorrência de intoxicações naturais causadas por micotoxinas cumarínicas, tais como a citrinina e a ocratoxina, coloca-nos diante da problemática relativa às intoxicações subclínicas por essas micotoxinas. $\mathrm{Na}$ realidade, pouco se conhece sobre a atividade imunomodulatória desses compostos. Reddy e colaboradores (1988) foram os primeiros investigadores a detectar alterações imunitárias em animais expostos à citrinina. Nesse trabalho, os autores identificaram uma linfopenia, induzida por exposições à citrinina, e sugeriram, ao mesmo tempo, que essa atuaria também como uma toxina imunoestimuladora. Assim, embora sendo capaz de induzir nefropatias em concentrações elevadas, em dosagens menores seria um imunoestimulador, a despeito de redu- 
zir a quantidade de linfócitos circulantes. Segundo Corrier (1991), a citrinina não causaria efeitos imunológicos importantes sobre aves ou mamíferos. No presente trabalho, procuramos identificar a ação imunomodulatória decorrente da exposição de camundongos albinos a baixas doses de citrinina, uma vez que, em experimentos anteriores, observaram-se efeitos antiinflamatórios marcantes causados por pequenas concentrações dessa micotoxina (Herzog-Soares, 1994; Souza et al.,1999). A dosagem de complemento e de anticorpos séricos de animais experimentalmente intoxicados, antes, simultaneamente e após a sensibilização com eritrócitos de carneiro estão representados nas Figuras 1 e 2.

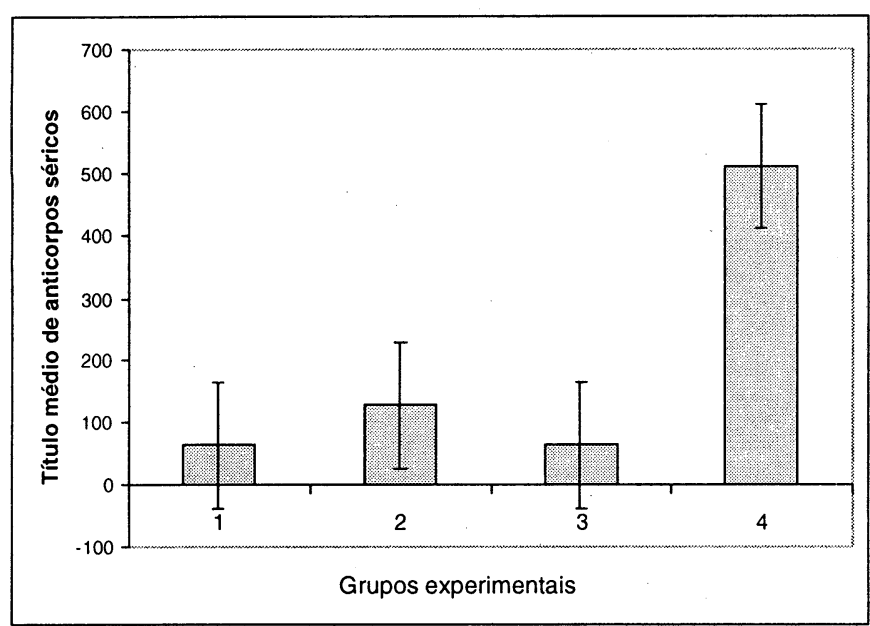

Figura 1: Título médio de anticorpos antieritrócitos de carneiro (SRBC) detectados em grupos de camundongos suíço-albinos (SW) tratados com 2,5 mg. Kg ${ }^{-1}$ de citrinina antes (1); concomitantemente (2) e após sensibilização (3) com SRBC a $2,5 \%$, em relação a um grupo controle não intoxicado (4). Os resultados são oriundos de três repetições para cada grupo de cinco animais e representam a média com $p<0,01$

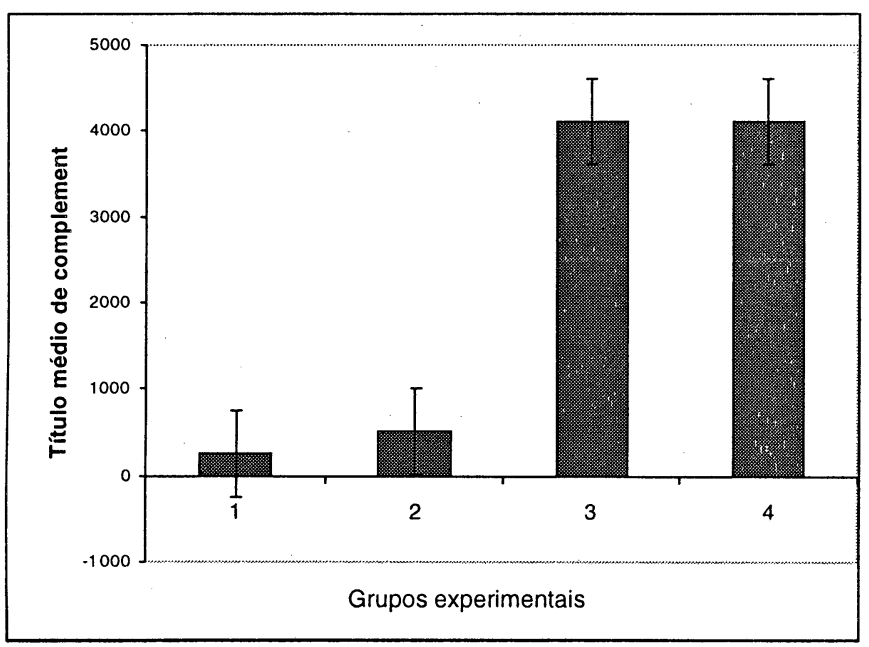

Figura 2: Título médio de complemento detectado em grupos de camundongos suiço-albinos (SW) tratados com 2,5 mg. $\mathrm{Kg}^{-1}$ de citrinina antes (1); concomitantemente (2) e após sensibilização (3) com SRBC a $2,5 \%$, em relação a um grupo controle não intoxicado (4). Os resultados são oriundos de três repetições para cada grupo de cinco animais e representam a média com $\mathrm{p}<0,01$
Os resultados obtidos sugerem, para os animais expostos à citrinina antes, ou depois da imunização com antígeno inerte, uma diminuição nos títulos médios de anticorpos específicos equivalente a $87,5 \%$. A exposição simultânea à imunização gerou uma diminuição de $75 \%$. Houve, também, uma marcante redução nos níveis de complemento circulante, detectada nos animais previamente intoxicados $(93,75 \%)$, ou intoxicados juntamente com a imunização $(87,5 \%)$. O título médio de anticorpos circulantes anti-eritrócitos de carneiro foi de 1:64 nos indivíduos expostos à citrinina antes ou após a imunização; 1:128 para aqueles que receberam o antígeno inerte concomitantemente à exposição à micotoxina; e 1:512 para os animais pertencentes ao grupo controle (não intoxicado). O título médio de complemento detectado foi de 1:256 nos animais previamente expostos; 1:512 naqueles que foram intoxicados ao mesmo tempo em que administrou-se o antígeno e 1:4096 para os animais que foram intoxicados após imunização, assim como para o grupo controle. A não interferência sobre a resposta adaptativa, quando a micotoxina foi administrada juntamente com o antígeno inerte, sugere a formação de complexos capazes de inibir a ação dessa micromolécula tóxica, conforme sugerido por outros trabaIhos experimentais (Freire, 1996, Souza et al.,1999).

Os efeitós contundentes sobre o funcionamento do sistema complemento corroboram com trabalhos anteriores onde detectou-se uma potente inibição na produção de citocinas e interferon para determinados grupos de micotoxinas, tais como fumonisinas e tricotecenos (Gerberick e Sorenson, 1983; Hughes et al., 1989; Qureshi e Hagler, 1992). Souza e colaboradores (1997) observaram que a supressão total da fagocitose, induzida por citrinina, tanto in vivo quanto in vitro, seria o resultado de um processo de esgotamento metabólico induzido por exposição a baixas doses de micotoxina. Ensaios realizados com a toxina T2 relatam a inibição na biossíntese de fibronectina como sendo a principal causa de efeitos inibitórios na fagocitose, porque afetaria, de modo direto, a ingestão de partículas e formação de fagossomas (Gerberick e Sorenson, 1983). Sendo assim, a interferência na resposta adaptativa estaria diretamente relacionada à incapacidade de processamento e apresentação dos antígenos disponibilizados para o sistema imunitário dos camundongos expostos à citrinina (Freire, 1996; Freire et al., 1996). Os níveis séricos mais baixos das proteínas do complemento, observado nos animais sensibilizados após exposição a citrinina, indicam que essa tende a mostrar-se mais imunotóxica para animais neonatos, que ainda não foram sensibilizados pelos diferentes patógenos do ambiente. De outro modo, o fato de ter havido uma significativa diminuição dos níveis de anticorpos dos animais intoxicados após a imunização sem, contudo, ocorrer uma diminuição significativa nos níveis de complemento, sugere um mecanismo diferenciado, relacionado à síntese de anticorpos. A inibição da síntese macromolecular, induzida por essa micotoxina foi observada in vitro, por Braunberg $e$ colaboradores (1992), que demonstraram que as micotoxinas citrinina e ocratoxina podem induzir pronunciada inibição dessa atividade, dependendo do tipo celular envolvido, bem como das concentrações das micotoxinas e da espécie animal estudada. Nesse experimento, os autores verificaram que citrinina em concentrações acima de $0,25 \mathrm{mg} \cdot \mathrm{mL}^{-1} \cdot 10^{-6}$ células, seria capaz de produzir inibição completa da síntese de proteínas, prejudicando, entre outras funções fisiológicas importantes, a resposta imune. 
A queda no título de anticorpos antieritrócitos de carneiro (anti SRBC) detectada nos animais expostos à citrinina, assemeIhou-se àquela observada por Hughes e colaboradores (1989) em camundongos expostos a diversos compostos macrocíclicos, do grupo dos tricotecenos, atingindo um percentual de até $73 \%$ de redução na produção primária (IgM), e de $10 \%$ na produção secundária (lgG). Do mesmo modo, Reddy e colaboradores (1988) demonstraram que a produção primária de anticorpos foi deprimida nos animais expostos a baixas doses de citrinina, aumentando, porém, quando os animais foram intoxicados com doses mais elevadas. Nesse ensaio, os animais foram sensibilizados após duas semanas de exposição crônica e contínua à citrinina em doses que variaram de 0,12 a $3 \mathrm{mg} . \mathrm{kg}^{-1}$. Assim sendo, o fato de havermos utilizado uma única exposição à citrinina $(2,5 \mathrm{mg}$. $\mathrm{Kg}^{-1}$ ) deveria originar resultados semelhantes aqueles relacionados as menores dosagens de citrinina empregadas por Reddy e colaboradores. O fato de que, no presente experimento, os animais foram tratados com uma dose que se aproxima da maior dose utilizada por esses autores, pode ser justificado pela possível ocorrência de detoxicação da citrinina inoculada, que tornou os níveis de micotoxina baixos o suficiente para produzirem diminuição da produção de anticorpos. De outro modo, o efeito imunoestimulante provocado por doses mais elevadas de citrinina parece ser controvertido, uma vez que outros experimentos assinalam a ocorrência de apoptose induzida por doses mais elevadas de citrinina, além de uma estimulação, caracterizada por prolife-

\section{Referências bibliográficas}

BRAUNBERG, R. C. GANTT, O., BARTON, C and FRIEDMAN, L. In vitro effects of the nephrotoxins Ochratoxin $A$ and citrinin upon biochemical function of porcine kidney. Arch. Environmental Contamination Toxicology. v. 22, p. 464-470, 1992.

CARVALHO, C. A. RIBEIRO, C. S., PEREIRA, A. A., CRUZ, L. C. H., FREIRE, RB Citrinin: Modulation chicken's lymphocyte blastogenesis. Proceedings of the 2nd Latinoamerican Mycotoxicology Congress. Maracay, Venezuela, 1997.

CORRIER, D. E. Mycotoxicosis: Mechanisms of immunossupression. Veterinary Immunology and Immunopathology. v. 30, p. 73-87, 1991.

FREIRE, R. B. Micotoxinas e resposta imune. In: CRUZ, L. C. H. (editor). Micotoxinas. perspectiva Latinoamericana, p. 141-148. Ed. Universidade Rural. UFRRJ, 1996, $261 \mathrm{p}$.

FREIRE, R. B. SOUZA, C. C., CRUZ, L. C. H. Humoral Immunoresponse Discontinuance caused by citrinin. In: International IUPAC Symposium on Mycotoxins and Phycotoxins p. 241 - PM 106, 1996.

GERBERICK, G. F., SORENSON, W. G. Toxicity of T2 toxin a Fusarium mycotoxin to alveolar macrophages in vitro. Envirom. Review v. 32, p. 269-285, 1983.

HERZO-SOARES, J. D. A. Efeito regulador da citrinina sobre macrófagos de galinhas da raça Leghorn. 1994. 87 p. Tese (Mestrado) - DMIV-UFRRJ, Rio de Janeiro.

HERZOG-SOARES, J. D. A. Relação parasito-hospedeiro: ação de subdoses de micotoxinas sobre a resposta imunitária em aves e mamíferos para coccídeas. 1997. $145 \mathrm{p}$. Tese (Doutorado) Parasitologia Veterinária - Medicina Veterinária - UFRRJ. ração inespecífica de linfócitos, porém mais relacionada a linfócitos T (Hughes et al., 1989; Freire et al., 1996; Carvalho et al., 1997 ; Souza et al.,1999).

Tendo-se em conta que as condições climáticas do Brasil envolvem altas temperaturas e elevada umidade, o crescimento de fungos produtores de micotoxinas ocorre de maneira generalizada. Praticamente todos os estados federativos brasileiros apresentam condições ambientais para a ocorrência de micotoxinas e de fungos produtores de micotoxinas durante todos os meses do ano. Assim, a ocorrência de baixas doses de citrinina é constante nas criações de animais mantidos sob confinamento, representando, por conseguinte, um fator de risco ambiental considerável que não está exclusivamente limitado a nenhuma das regiões do país.

\section{Conclusão}

Os resultados obtidos no presente trabalho nos permitem concluir que a citrinina é imunotóxica para animais jovens, comprometendo tanto a resposta humoral adaptativa como a resposta natural quando assimiladas em baixas concentrações, mesmo que após uma só exposição. Assim sendo, os animais em idade de vacinação representam um grupo de risco para o qual deve-se dar mais atenção, especialmente porque essa micotoxina pode comprometer sua capacidade de resposta às diferentes vacinas, sem sintomas clínicos indicativos de imunossupressão, ou intoxicação.

HUGHES, B. J., HIESH, G. C., JARVIS, B. B., SHARMA, R. P, Effects of macrociclic Thrichothecene mycotoxins on the immune system. Arch. Envirom. Contam. Toxicol. v. 18, p. 388-395, 1989.

HUDSON, L., HAY, F. Complement In: 3rd edition. p. 264-280. Blackwell Scientific Co. 1989.

QURESHI, M. A., HAGLER JR, W. M. Effect of Fumonisin B1 Exposure on Chicken Macrophage Fuctions in vitro. Poultry Science, v. 71, p.104-112, 1992.

REDDY, R. V., TAYLOR, M. J. and SHARMA, R. P. Evaluation of citrinin toxicity on the immune functions of mice. Journal of Food Protection. v. 51, p. 32-36, 1988.

SOUZA, M. M. S. Citrinina: Efeitos Imunomoduladores sobre as Respostas Inflamatória e Celular em Camundongos Albinos. 1996. 118 p. Tese (Mestrado) - DMIV-UFRRJ, Rio de Janeiro,

SOUZA, M. M. S., FREIRE, R. B., SOUZA, C.C., CRUZ, L. C. H. Supressão da resposta inflamatória por exposição à citrinina: proposta de mecanismo de ação. R. bras. Med. Vet. v. 19, n.1, p. 2830, 1997.

SOUZA, M. M. S., FREIRE, R. B., CARVALHO, C. A. Avaliação da ação imunomodulatória da citrinina através da estimulação da blastogênese linfocitária. R. bras. Med. Vet.v. 21, n. 2, p. 69-71. 1999.

TERSE, P. S., MADHYASTHA, M. S., ZUROVAC, O., STRINGFELLOW, D., MARQUARDT, R. R. and KEIPPAONEN, B. W. Comparison of in vitro and in vivo biological activity of mycotoxins. Toxicon v. $31, \mathrm{n}$. 7, p. 913-919, 1993. 